$C_{E P} \ll \quad$ ISSN: $2289-8085$

\title{
EDITORIAL
}

\section{Trends and Common Challenges of Online Teaching and Learning}

We would like to welcome you to the special issue of IIUM Journal of Educational Studies (IUES), a peer-reviewed scholarly journal concerned with interdisciplinary and multidisciplinary educational issues. This special issue comprises papers accepted to the Fourth International Conference on Engineering Professional Ethics and Education (ICEPEE'21) with the theme "Redesigning Teaching and Learning for Sustainable Education". The 4th ICEPEE'2 1 focuses on bringing together educators and practitioners to address the latest trends and common challenges in the conduct of online teaching and learning. The conference aims to provide a platform for discussion on the most pressing topics including ethics, recent innovations and technology, effective methodologies and assessments in online teaching and learning amongst others. Six papers have been selected for this special issue and we are delighted to share these contributions with you.

We would like to acknowledge the contribution from many people, namely the authors, reviewers, editorial board of IJES, who made this special issue possible. We would also like to extend our gratitude to INTEGRATES (Integrative Engineering Education and Ethics for Sustainability) and the Kulliyyah of Engineering for their continuous guidance and support.

Best regards,

Prof. Dr. Aisha Hassan Abdalla Hashim

Prof. Ir. Dr. Zuraida Ahmad

Guest Editors of IIUM Journal of Educational Studies (Special Issue), International Conference on Engineering Professional Ethics \& Education (ICEPEE'21), International Islamic University, Malaysia.

October 20, 2021 